\title{
OXYGENATION BY HOLLOW PLUNGING WATER JET
}

\author{
Er. Surinder Deswal, Ph.D. \\ Asst. Prof. Civil Engineering Department, National Institute of Technology, \\ KURUKSHETRA-136119. Haryana. India.
}

\begin{abstract}
Oxygenation by a plunging water jet is a more attractive way to effect oxygen-transfer than conventional oxygenation systems. A lot of work has been reported on the oxygen-transfer by plunging water jets. However, few studies have been carried out on hollow plunging jet. In this paper, volumetric oxygen-transfer coefficient and oxygen-transfer efficiency has been studied experimentally for hollow plunging jet in a pool of water for different thicknesses of jets. This research suggests that the volumetric oxygen-transfer coefficient and oxygen-transfer efficiency of the hollow plunging jet for air-water system are competitive with other types of aeration systems. Further, relationships of volumetric oxygen-transfer coefficient with jet power per unit volume and jet parameters are also proposed. The suggested relationships predict the volumetric oxygen-transfer coefficient for hollow plunging water jet within a scatter of $\pm 15 \%$.
\end{abstract}

Key words: hollow plunging jet, oxygenation, volumetric oxygen-transfer coefficient, oxygentransfer efficiency, jet power.

\section{INTRODUCTION}

It is well known that a water jet, which after passing through the surrounding atmosphere plunges into a water pool, entrains into this pool a substantial amount of air and forms a submerged two-phase region with a considerable air-water interfacial area. This process is called plunging water jet entrainment and aeration (or oxygenation). It is basically a combination of hydrodynamic and aerodynamic forces interacting between water jet and ambient air. Plunging jet applications include aeration and floatation in water and wastewater treatment, oxygenation of mammalian-cell bio-reactors, biological aerated filter, fermentation, bubble floatation of minerals, plunging columns, cooling system in power plants, stirring of chemicals as well as increasing gas-liquid transfer, plunging breakers and waterfalls (Bin 1993; Cummings 1997; Chanson et al. 2004; Leung et al. 2006). Oxygenation by a plunging water jet is a more attractive way to effect oxygen-transfer than conventional oxygenation systems for various reasons
(Kusabiraki et al. 1990; Bin 1993; Emiroglu and Baylar 2003): it does not require an air compressor; it facilitates make-up of the "closed" system, which enhance complete utilization of oxygen and volatile reactants; it is simple in design, construction and operation; it does not require separate stirring device because the water jet itself achieves aeration and mixing; it is energetically attractive as a means of straightforward contacting mechanism in fouling or hazardous environments; and it is free from operational difficulties such as clogging in air diffusers, limitations on the installation of mechanical aerators by the tank width, etc. Supported by these potential advantages, there has been a growing interest in the oxygenation by plunging water jets in the last few years.

A substantial number of researchers have studied air-water oxygen transfer by plunging jets. Experimental studies on the oxygen transfer by plunging water jets were carried out by van de Sande and Smith (1975), Tojo and Miyanami (1982), Tojo et 
al. (1982), Bin and Smith (1982), Bonsignore et al. (1985), Ohkawa et al. (1986), and Funatsu et al. (1988). These and the other related studies were reviewed in detail by Bin (1993). Recently, Yamagiwa et al. (2001) studied the effects of liquid property on air entrainment and oxygen transfer rates of plunging jet reactors and Leung et al. (2006) investigated the air/water oxygen transfer in a biological aerated filter. Further, some of these researchers have presented their data in the form of empirical relationships. The simplest relationships for conventional plunging water jets are recommended by, Bin and Smith (1982) (Eq.1) and by Tojo and Miyanami (1982) (Eq.2):

$$
\begin{aligned}
& K_{L} A_{(20)}=9 \times 10^{-5} P \\
& K_{L} a_{(20)}=0.029(P / V)^{0.65}
\end{aligned}
$$

where $K_{L} A_{(20)}$ is volumetric oxygen transfer factor at standard conditions $\left(\mathrm{m}^{3} / \mathrm{h}\right) ; v_{j}$ is jet velocity at exit $(\mathrm{m} / \mathrm{s}) ; d_{j}$ is jet diameter $(\mathrm{m})$; $P$ is jet power (W); $K_{L} a_{(20)}$ is volumetric oxygen transfer coefficient at standard conditions $(1 / \mathrm{s})$; and $P / V$ is jet power per unit volume $\left(\mathrm{kW} / \mathrm{m}^{3}\right)$. Thus much useful information is available on the oxygen transfer characteristics of conventional plunging water jets.

These and other researchers have identified jet velocity, jet diameter, jet plunge angle and jet power (which is a function of jet velocity and jet diameter) as the four operating variables affecting the oxygen transfer of a plunging water jet aeration system. However, it is insufficient to investigate or discuss the oxygen transfer by plunging jet oxygenation system only by these four factors. An important factor that cannot be overlooked is geometry/shape of the jet in the oxygenation system. A review of works carried out on different geometries of plunging jets so far suggests that most of these works were carried out on conventional shapes of plunging jets. Chanson and Brattberg (1998) investigated air entrainment by two-dimensional planner plunging jet; Bagatur et al. (2002) investigated entrainment by oval and rectangular (with rounded ends) plunging jets; and Emiroglu and Baylar (2003) have reported oxygentransfer by venturi type circular plunging jet. So far only circular, rectangular (with rounded ends), and oval shapes of plunging jets have been studied. In the present study, a cylindrical shaped plunging aeration device is fabricated to generate hollow plunging jet (Fig. $1 \& 2$ ) to investigate oxygen transfer (in terms of volumetric oxygen-transfer coefficient at standard conditions $K_{L} a_{(20)}$ and oxygen-transfer efficiency $O E$ ) by a hollow plunging jet. The relationships, for hollow inclined plunging jet, are also presented to predict volumetric oxygentransfer coefficient $K_{L} a_{(20)}$ as a function of jet power or jet parameters.

Insert Fig.1 \& Fig.2

\section{OXYGEN-TRANSFER BY WATER JETS}

In the "closed" system of the plunging liquid jet aerators, perfect mixing for the liquid phase in the pool and plug flow in the circulation pipe can be assumed (Bin 1993). In such a case, an oxygen balance equation relating the instantaneous rate of change in dissolved oxygen (DO) concentration $(d C / d t)$ to the rate of oxygen mass transfer between air and water can be written as:

$\frac{d C}{d t}=K_{L} \frac{A}{V}\left[C_{s}-C\right]$

where $K_{L}$ is bulk liquid film coefficient.; $C_{s}$ is the saturation dissolved oxygen concentration in water at prevailing ambient conditions; $A$ is the air-water contact area; 
and $V$ is the volume of water associated with this. The term $A / V$ is called the specific surface area $(a)$ or surface area per unit volume; while the term $K_{L} A$ is called the volumetric oxygen-transfer factor. Integrating Eq.4 between the limits of $C=C_{0}$ and $C=C$ and $t=0$ and $t=t$, $\int_{C_{0}}^{C} \frac{d C}{C_{S}-C}=\left(K_{L} a\right) \int_{0}^{t} d t$

which after simplification, Eq. 5 can be written as:

$K_{L} a=\frac{1}{t} \ln \left[\frac{C_{S}-C_{0}}{C_{S}-C_{t}}\right]$

where $C_{0}$ and $C_{t}$ are dissolved oxygen concentrations in the water at start and at the time $t$ of aeration respectively; and $K_{L} a$ is volumetric oxygen-transfer coefficient. Eq.6 shows that values of $K_{L} a$ can be obtained by substituting the measured values of $C_{S}$, $C_{0}, C_{t}$ and $t$. In order to have a uniform basis for comparison of different systems, $K_{L} a$ is generally normalized at $20^{\circ} \mathrm{C}$ standard. The temperature dependence of $K_{L} a$ can be expressed (Daniil and Gulliver 1998) using the following empirical equation:

$K_{L} a_{(20)}=K_{L} a_{(T)} \times(1.024)^{(20-T)}$

where $K_{L} a_{(20)}$ is oxygen-transfer coefficient at standard conditions $(1 / \mathrm{s}) ; \quad K_{L} a_{(T)}$ is oxygen-transfer coefficient at $T^{\mathrm{O}} \mathrm{C}(1 / \mathrm{s})$; and $T$ is water temperature $\left({ }^{0} \mathrm{C}\right)$.

The oxygenation performance of plunging water jets is generally expressed in terms of the oxygen-transfer efficiency $O E \quad(\mathrm{~kg}$ $\mathrm{O}_{2} / \mathrm{kW} . \mathrm{h}$ ), and give by Eq.7

$O E=\frac{O_{R} V}{P}$

where $O_{R}$ is oxygen-transfer rate $(\mathrm{mg} / \mathrm{L} / \mathrm{h})$ at $20^{\circ} \mathrm{C}$ and 1 atmosphere (standard conditions); and $P$ is jet power $(\mathrm{kW}) . O_{R}$ and $P$ can be expressed as:

$O_{R}=K_{L} a_{(20)} \cdot 3600 . C_{S}^{*}$

$P($ in $k W)=\left(\frac{1}{2} \rho Q v_{j}^{2}\right) \frac{1}{10^{3}}$

$=\left(\frac{\pi}{8} \rho n t_{j}^{2} v_{j}^{3}\right) \frac{1}{10^{3}}$

where $C_{S}^{*}$ is saturation dissolved oxygen (DO) concentration in water at standard conditions $(\mathrm{mg} / \mathrm{L}) ; \rho$ is density $\left(\mathrm{kg} / \mathrm{m}^{3}\right) ; Q$ is discharge or jet flow rate $\left(\mathrm{m}^{3} / \mathrm{s}\right) ; v_{j}$ is jet velocity at exit $(\mathrm{m} / \mathrm{s})$ and $t_{j}$ is jet thickness (m).

\section{EXPERIMENTATION}

\subsection{Experimental setup}

In the present study, a "closed" system with a complete re-circulation of the water and a constant water holdup was used to conduct the experiments. A schematic representation of the experimental set-up is shown in Fig.3. The experimental set-up consists of a water tank, a water pump, a flow-regulating valve, an orifice meter, a thermometer, a hollow plunging jet device, a piezometer and a scale. All experiments on oxygen-transfer by hollow plunging jet were carried out in a water tank with dimensions of $1.02 \mathrm{~m}$ long $\mathrm{x}$ $1.02 \mathrm{~m}$ wide $\mathrm{x} 1.0 \mathrm{~m}$ deep. The water-depth in the tank was kept at $0.6 \mathrm{~m}$ for all experiments and measured with the help of a piezo meter fitted to the water tank alongside a scale. The water in the experimental set-up was circulated by a centrifugal pump. A flow regulating valve was provided at the location identified in Fig.3. A pre-calibrated orifice meter was installed in the pipeline for flow measurements. A digital thermometer was used for the temperature measurement. The hollow jet device was fitted to the 
vertical inflow pipe and adjusted such that the jet impinges vertically and centrally in the pool. The vertical distance between exit of the jet and water surface in the pool, was kept as $0.1 \mathrm{~m}$ through out the experimentation.

Insert Fig.3

\section{HOLLOW PLUNGING JET DEVICE}

The hollow plunging jet device has two main components, namely (1) a cylinder and (2) a socket. Three cylinders, having diameters of $45.40 \mathrm{~mm}, 47.64 \mathrm{~mm}$ and $49.45 \mathrm{~mm}$ respectively, were fabricated of Perspex. The upper portion of each cylinder has been tapered for making the flow smooth as shown in Fig.2(a). The fabricated socket (Fig.2b) has internal threads so that it can be fitted to the inflow pipe (internal diameter $=$ $53.34 \mathrm{~mm}$ ), after placing and fixing the solid cylinder in the socket (Fig.2c). When the device is fitted to the inflow pipe (Fig.2d), the hollow plunging jets are generated as the water flows through the annular space between the inflow pipe and the solid cylinder (Fig.1). With the three fabricated cylinders, hollow plunging jets of $3.97 \mathrm{~mm}$, $2.85 \mathrm{~mm}$ and $1.95 \mathrm{~mm}$ jet thickness $\left(t_{j}\right)$ can be generated.

\subsection{Experimental procedure}

In this study, a series of laboratory experiments were carried out on hollow plunging water jet to study its volumetric oxygen-transfer coefficient $\left(K_{L} a\right)$ and oxygen-transfer efficiency $(O E)$. The experiments were performed on three jet thickness, $t_{j}=1.95,2.85$ and $3.97 \mathrm{~mm}$. Each of these three hollow jets were tested at four different jet flow rates or discharges, viz., $1.33 \times 10^{-3}, 1.8 \times 10^{-3}, 2.5 \times 10^{-3}$ and $3.1 \times 10^{-}$

${ }^{3} \mathrm{~m}^{3} / \mathrm{s}$. To begin with an experiment, the hollow plunging jet device was fitted to the inflow pipe. Tap water was then filled in the water tank. The opening of the regulating valve was set at desired flow rate using the pre-calibrated orifice meter in the supply line. Water in the tank was deoxygenated by adding an estimated quantity of sodium sulfite $\left(\mathrm{Na}_{2} \mathrm{SO}_{3}\right)$ and in addition cobalt chloride $\left(\mathrm{CoCl}_{2}\right)$ was added to act as a catalyst. A representative sample of the deoxygenated water was taken and the initial dissolved oxygen concentration $\left(C_{0}\right)$ was determined by azide modification method (APHA 2005). Aeration was then carried out for a fixed duration of time ( $t=60$ seconds). The representative samples of the aerated/oxygenated water were taken for the determination of dissolved oxygen concentration after time $t\left(C_{t}\right)$. The water temperature $(T)$ was recorded during the course of experiment. The value of $K_{L} a_{(T)}$ was then calculated by using Eq.5 and volumetric oxygen-transfer coefficient at standard conditions $\left(K_{L} a_{(20)}\right)$ was obtained by using Eq.6. The $O E$ and $P$ values were calculated by using Eq.7 and Eq.9 respectively.

\section{RESULTS AND DISCUSSIONS}

The following sections discuss the variation of $K_{L} a_{(20)}$ values for hollow plunging water jet with the jet velocity $v_{j}$ and jet power per unit volume $P / V$; the derivation of empirical relationships of $K_{L} a_{(20)}$ with jet power and jet parameters; and the variation of $O E$ of hollow plunging water jet.

The effect of jet velocity on volumetric oxygen-transfer coefficient of hollow plunging jets is shown in Fig. 4. It is observed that $K_{L} a_{(20)}$ increases remarkably with increasing value of $v_{j}$; and for a given jet velocity, the thicker jets have higher $K_{L} a_{(20)}$ values in all the experiments. This 
increase in $K_{L} a_{(20)}$ with increase in jet velocity may be ascribed due to the increase in momentum of the jet flow and/or increase of jet power. The relationship between the volumetric oxygen-transfer coefficient $\left(K_{L} a_{(20)}\right)$ and the jet velocity $\left(v_{j}\right)$, depending upon the jet thickness $\left(t_{j}\right)$, can be expressed (Fig. 4) by:

$$
K_{L} a_{(20)} \propto v_{j}^{1.85-1.98}
$$

\section{Insert Fig. 4 \& Insert Fig. 5}

To study the combined effect of jet velocity $\left(v_{j}\right)$ and jet thickness $\left(t_{j}\right)$ on the volumetric oxygen-transfer coefficient, the $K_{L} a_{(20)}$ data for hollow jets are compared in Fig. 5 in terms of the jet power per unit volume $(P / V)$. It was observed that the values of $K_{L} a_{(20)}$ increases with the increase in jet power per unit volume over the whole range of experiments. For predicting the volumetric oxygen-transfer coefficient $K_{L} a_{(20)}$ by hollow plunging water jets, the following relationships between $K_{L} a_{(20)}$ and $P / V$ was obtained from the plot between $K_{L} a_{(20)} \quad \mathrm{v} / \mathrm{s}$ $P / V$ (Fig.5):

$$
K_{L} a_{(20)}=0.038(P / V)^{0.61}
$$

The above relationship (Eq.11) is similar to expressions proposed by Bin and Smith (1982) (Eq.1) and by Tojo and Miyanami (1982) (Eq.2) for conventional plunging jets. A correlation coefficient value of 0.99 was obtained between the experimental and predicted values of $K_{L} a_{(20)}$ using Eq.11. A plot between experimental and predicted $K_{L} a_{(20)}$ values obtained by using Eq.11, shows a scatter within $\pm 15 \%$ of the line of perfect agreement (Fig. 6a). Further, when a multivariate linear regression was applied to formulate an equation/relationship between $K_{L} a_{(20)}$ for hollow plunging water jets and jet parameters represented by $P$ (i.e. $v_{j}$ and $t_{j}$ ). The following relationship was developed:

$$
K_{L} a_{(20)}=0.103 n^{0.81} v_{j}^{2.11} d_{j}^{1.43}
$$

The correlation coefficient between the experimental values of $K_{L} a_{(20)}$ and predicted values of $K_{L} a_{(20)}$ using Eq.12 was 0.992. A plot between experimental $K_{L} a_{(20)}$ and predicted $K_{L} a_{(20)}$ values obtained by using Eq.12, shows a scatter within $\pm 15 \%$ of the line of perfect agreement (Fig. 6b). Thus, Eq.11 as well as Eq.12 can be helpful in providing information about the oxygentransfer of hollow plunging jets with fair precision. A simple selection of jet velocity (in $\mathrm{m} / \mathrm{s}$ ) and jet thickness (in $\mathrm{m}$ ) is therefore sufficient to predict the volumetric oxygentransfer coefficient (in 1/s) for hollow plunging jet.

Insert Fig. 6

Fig.7 show the oxygen-transfer efficiency $(O E)$ for hollow plunging jet as a function of jet power per unit volume $(P / V)$. It was observed that oxygen-transfer efficiency decreases as the jet power per unit volume increases for hollow plunging jet as in the case of all other types of oxygenation/aeration devices. In the present study, the oxygen-transfer efficiency of hollow plunging water jet is in the range of $1.91-10.04 \mathrm{~kg} \mathrm{O}_{2} / \mathrm{kW}$.h. Table 1 provides a comparison of oxygen-transfer efficiency of the hollow plunging jet with other types of aeration/oxygenation equipments. It can be observed from this table that the hollow plunging jet device studied here is quite competitive with the other conventional aeration/oxygenation equipments.

Insert Fig. $7 \&$ Insert Table 1 


\section{CONCLUSIONS}

In this study, a series of laboratory experiments were carried out to obtain the values of the volumetric oxygen-transfer coefficient and the oxygen-transfer efficiency of hollow plunging water jets. Based on the findings of this study, the following conclusions can be drawn:

- The volumetric oxygen-transfer coefficient for the hollow plunging jet increases with the increase in jet velocity. For a given jet velocity, the $K_{L} a_{(20)}$ values increases with increase in the jet thickness.

- The volumetric oxygen-transfer coefficient for hollow plunging water jet increases with the increase in the jet power per unit volume.

- The volumetric oxygen-transfer coefficient for hollow plunging water jets is well correlated with the jet power per unit volume and jet parameters (representing jet power). The relationships, represented by Eq.11 and Eq.12, predict the $K_{L} a_{(20)}$ within a scattering range of $\pm 15 \%$. The relationships would be quite useful in comparing the performance of hollow plunging jets of different configurations.

- The oxygen-transfer efficiency of hollow plunging water jet is very much competitive with the other conventional aeration/oxygenation equipments and thus suggests their practical application.

\section{ACKNOWLEDGEMENT}

The author is thankful to Civil Engg. Deptt. of N. I. T. Kurukshetra for providing necessary funding and facilities to carry out this research. The author is Asstt. Prof., Civil Engineering Department, National Institute of Technology, Kurukshetra-136119. Haryana. India.

\section{REFERENCES}

[1] APHA, AWWA and WEF (2005). Standard methods for the examination of water and wastewater (21st ed.). Washington DC: American Public Health association.

[2] Bagatur, T., Baylar, A. \& Sekardag, N. (2002). The effect of nozzle type on air entrainment by plunging water jets. Water Qual. Res. J. Canada, 37(3), 599-612.

[3] Bin, A.K. \& Smith, J.M. (1982). Mass transfer in a plunging liquid jet absorber. Chem. Engng. Commun., 15, 367-383.

[4] Bin, A.K. (1993). Gas entrainment by plunging liquid jets. Chem. Eng. Sci. J. Great Britain, 48, 3585-3630.

[5] Bonsignore, D., Volpicelli, G., Campanile, A., Santoro, L. \& Valentino, R. (1985). Mass transfer in plunging jet absorbers. Chem. Eng. Process, 19, 85-94.

[6] Chanson, H. \& Brattberg, T. (1998). Air entrainment by two-dimensional plunging jets: the impingement region and the very-near flow field. Proc. ASME FEDSM'98. Washington DC, 18.

[7] Chanson, H., Aoki, S. \& Hoque, A. (2004). Physical modelling and similitude of air bubble entrainment at vertical circular plunging jets. Chem. Eng. Sc., 59, 747-758.

[8] Cummings, P.D. \& Chanson, H. (1997). Air entrainment in the developing flow region of plunging jets-part 1: theoretical development. Fluids Eng. J. ASME, 119, 597-602.

[9] Daniil, E.I. \& Gulliver, J.S. (1988). Temperature dependence of liquid film coefficient for gas transfer. J. Environ. Eng., 114(5), 1224-1229.

[10] Emiroglu, M.E. \& Baylar, A. (2003). Study of the influence of air holes along length of convergent-divergent passage of a venture device on aeration. J. Hyd. Res., 41(5), 513-520. 
[11] Funatsu, K., Hsu, Y.Ch., Noda, M. \& Sugawa, S. (1988). Oxygen transfer in the water jet vessel. Chem. Eng. Commun., 73, 121-139.

[12] Kusabiraki, D., Niki, H., Yamagiwa, K. \& Ohkawa, A. (1990). Gas entrainment rate and flow pattern of vertical plunging liquid jets. The Canadian J. Chem. Eng., 68, 893-903.

[13] Leung, S.M., Little, J.C., Hoist, T. \& Love, N.G. (2006). Air/water oxygen transfer in a biological aerated filter. $J$. Environmental Eng.,132(2), 181-189.

[14] Ohkawa, A., Kusabiraki, D., Shiokawa, Y., Sakal, M. \& Fujii, M. (1986). Flow and oxygen transfer in a plunging water system using inclined short nozzles in performance characteristics of its system in aerobic treatment of wastewater. Biotech. Bioeng., 28, 1845-1856.

[15] Tojo, K. \& Miyanami, K. (1982). Oxygen transfer in jet mixers. Chem. Eng. J. Netherlands, 24, 89-97.

[16] Tojo, K., Naruko, N. \& Miyanami, K. (1982). Oxygen transfer and liquid mixing characteristics of plunging jet reactors. Chem. Eng. J. Netherlands, 25, 107-109.

[17] van de Sande, E. \& Smith, J.M. (1975). Mass transfer from plunging water jets. Chem. Eng. J. Netherlands, 10, 225-233.

[18] Yamagiwa, K., Ito, A., Kato, Y., Yoshida, M. \& Ohkawa, A. (2001). Effects of liquid property on air entrainment and oxygen transfer rates of plunging jet reactor. J. Chem. Eng. Japan, 34(4), 506-512.

Table 1 Oxygen-transfer efficiency for various types of equipments.

\begin{tabular}{|l|ll|c|}
\hline S.N. & \multicolumn{2}{|c|}{ Equipment } & $\begin{array}{c}\text { OE } \\
\left(\mathrm{kg} \mathrm{O}_{2} / \mathrm{kW} . \mathrm{h}\right)\end{array}$ \\
\hline \multirow{2}{*}{$1^{*}$} & $\begin{array}{l}\text { Small bubble size } \\
\text { disperger }\end{array}$ & $1.36-1.8$ \\
\cline { 2 - 4 } $2^{*}$ & Large bubble size & 0.95 \\
\hline
\end{tabular}

\begin{tabular}{|l|l|c|}
\hline & disperger & 0.64 \\
\hline $3^{*}$ & Turbine agitator & $1.2-1.38$ \\
\hline $4^{*}$ & $\begin{array}{l}\text { Surface aeration by } \\
\text { mechanical agitator }\end{array}$ & 1.68 \\
\hline $5^{*}$ & Deep shaft aerator & $3.0-6.0$ \\
\hline $6^{*}$ & Gas jet aerator & 1.64 \\
\hline $7^{*}$ & Eddy jet mixer & 4.78 \\
\hline $8^{*}$ & Plunging Jet & $0.92-3.9$ \\
\hline $9^{\#}$ & $\begin{array}{l}\text { Plunging venturi } \\
\text { device }\end{array}$ & $2.2-8.8$ \\
\hline $10^{\wedge}$ & $\begin{array}{l}\text { Hollow plunging jet } \\
\left(\theta=60^{0}\right)\end{array}$ & $1.91-10.04$ \\
\hline
\end{tabular}

* Cited from Tojo and Miyanami (1982)

\# Emiroglu and Baylar (2003)

$\wedge$ Present study

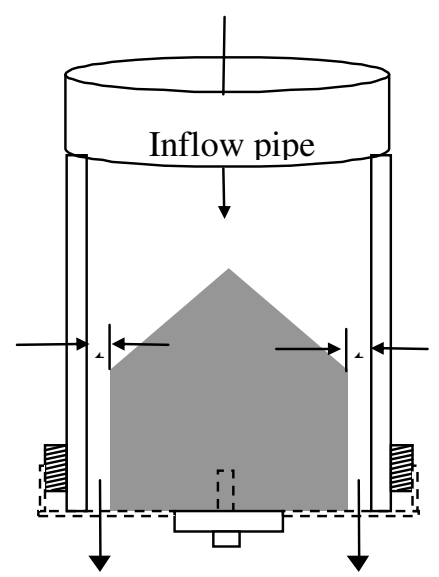

Fig. 1. Line diagram of hollow plunging jet device fitted to the inflow pipe.

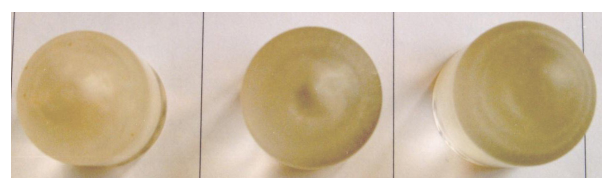

(a) Perspex cylinders

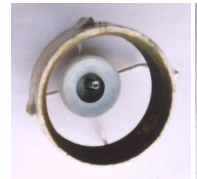

(b) Socket

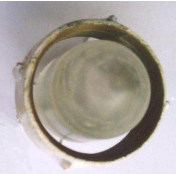

(c) Hollow plunging jet device

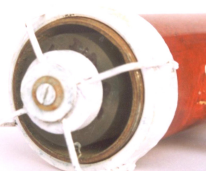

(d) Jet device fitted to inflow pipe
Fig. 2. Details of hollow plunging jet device. 


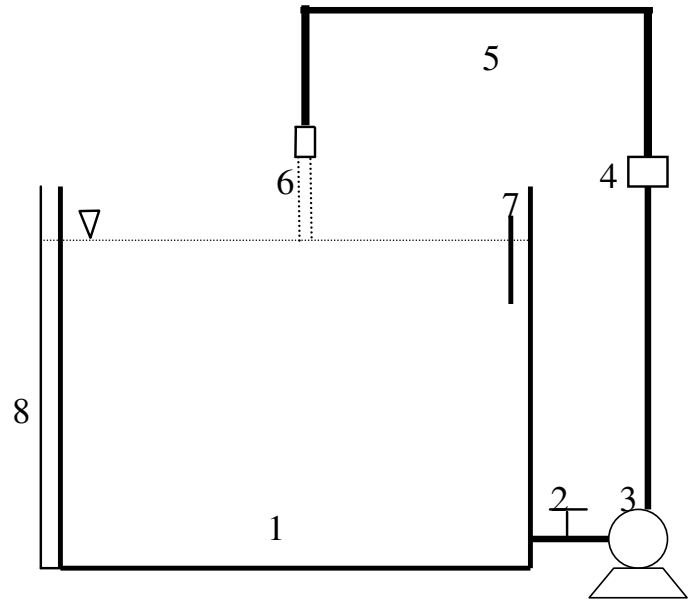

Fig. 3. Experimental set-up: (1) water tank; (2) flow regulating valve; (3) water pump; (4) orifice meter; (5) inflow pipe; (6) hollow plunging jet device; (7)

Thermometer probe; (8) piezo meter with scale.

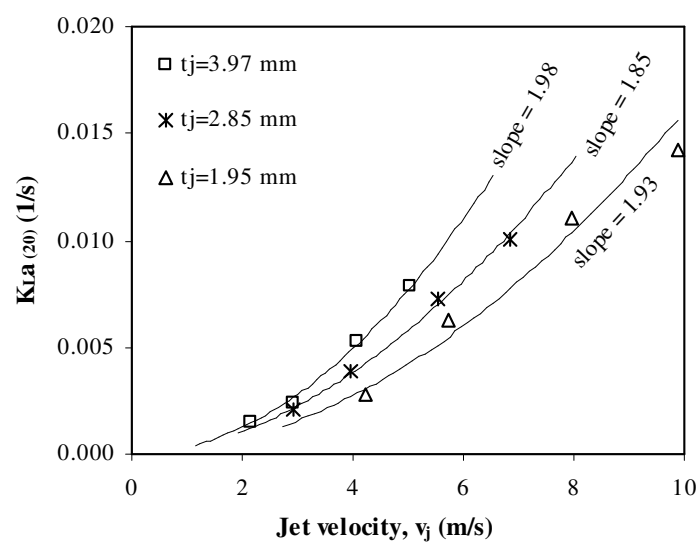

Fig. 4. Oxygen transfer as a function of jet velocity

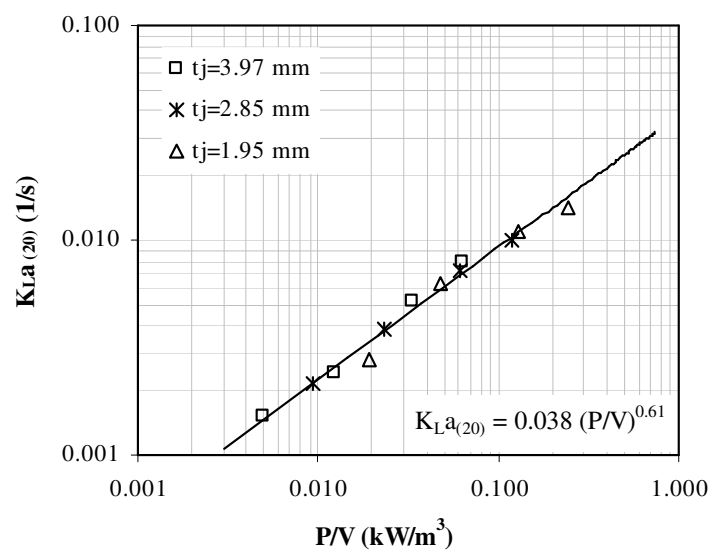

Fig. 5. Oxygen transfer as a function of jet power

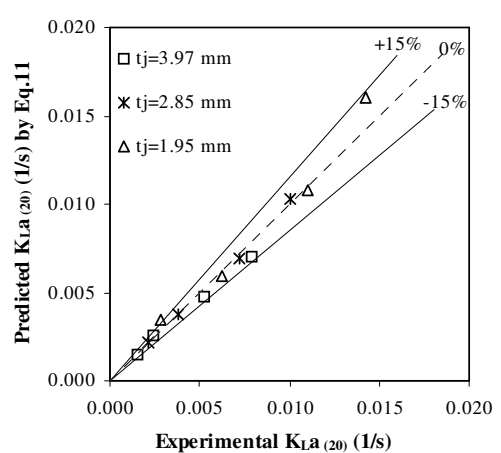

(a)

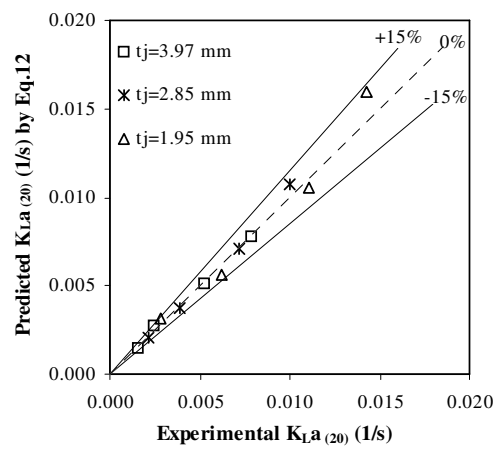

(b)

Fig 6. Experimental $\mathbf{K}_{\mathrm{L}} \mathbf{a}_{(\mathbf{2 0 )}} \mathrm{v} / \mathrm{s} \mathbf{K}_{\mathrm{L}} \mathbf{a}_{(\mathbf{2 0 )}}$

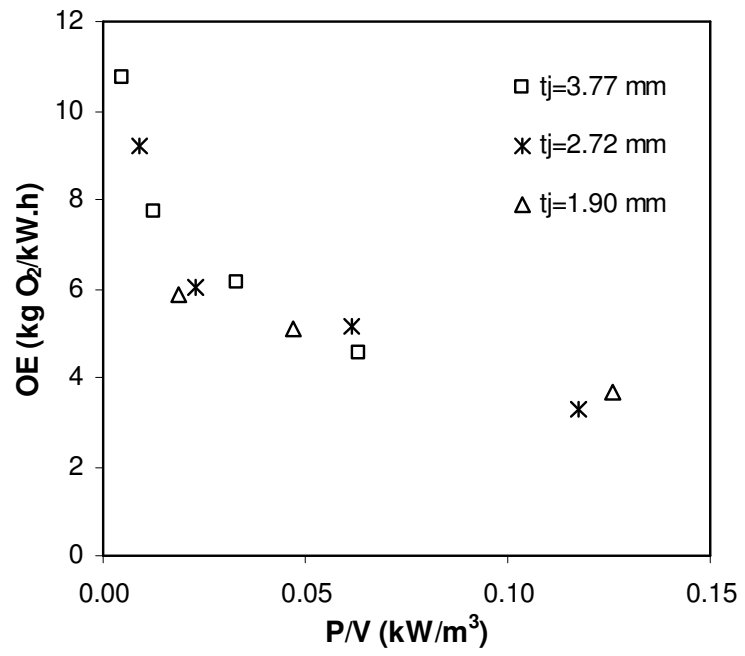

Fig 7. Variation of oxygen-transfer efficiency 
